\title{
Análise da relação entre aptidões cerebrais e competências gerenciais: o caso de uma empresa têxtil
}

\section{Analysis of the relationship between cerebral abilities and management competences: a textile company case}

\author{
Maurício Capobianco Lopes ${ }^{1}$ \\ Francisco Antonio Pereira Fialho ${ }^{1}$ \\ Juliana Leonardi ${ }^{1}$ \\ Luiz Fernando Lopes ${ }^{1}$ \\ Samuel Fernandes Ribeiro' \\ Pedro Paulo Hugo Wilhelm²
}

\begin{abstract}
Resumo: Relacionar modelos mentais com competências gerenciais pode ser um fator de vantagem competitiva para as organizações. Baseado neste pressuposto, o objetivo deste artigo é relacionar aptidões cerebrais dominantes com competências gerenciais exigidas em determinados setores de uma empresa, a partir de uma abordagem metodológica descritiva quantitativa. Para isto, foi realizado um levantamento com 127 gerentes de nível tático operacional em uma empresa têxtil de médio porte no Estado de Santa Catarina, aplicando-se o instrumento de identificação de aptidões cerebrais dominantes proposto por Miranda (1997). Os resultados obtidos com este instrumento foram relacionados e analisados com base nas funções executadas pelos funcionários e no modelo de competências gerenciais proposto por Quinn et al. (2003). Pode-se comprovar pelas análises realizadas a relação direta entre os elementos abordados, além de se verificar a importância da pesquisa como instrumento de gestão do capital humano das organizações.
\end{abstract}

Palavras-chave: Gestão do conhecimento. Competências gerenciais. Aptidões cerebrais.

\begin{abstract}
Relating mental models to competencies and abilities may be a competitive advantage factor for organizations. Based on these assumptions, this article aims to relate brain dominance skills to managerial competencies required in a company. Descriptive and quantitative analysis was the methodological approach used. Thus, a survey was conducted with 127 tactical operational managers at a medium-sized textile company in the state of Santa Catarina, Brazil, applying a tool proposed by Miranda (1997) to identify brain dominance skills. The results obtained with this tool were correlated and analyzed based on the functions performed by the employees in the competencies managerial model proposed by Quinn et al. (2003). Thus, we establish a direct relationship between the elements addressed, and present the importance of this kind of tool as a human capital management instrument in the organizations.
\end{abstract}

Keywords: Knowledge management. Managerial competences. Brain dominance skills.

\section{Introdução}

As mudanças sociais, culturais e de inovações tecnológicas têm forçado as empresas a readaptarem suas estruturas, estratégias e formas de trabalho. Cada vez mais se acentua a necessidade de profissionais competentes, sobretudo daqueles que comandam as organizações, para a adaptação e sobrevivência em um mercado altamente competitivo e baseado no conhecimento.

O conhecimento tem se firmado como um elemento essencial para qualquer nível de atividade organizacional. Stankosky (2005) salienta que o conhecimento é a informação que tem valor, é

\footnotetext{
${ }^{1}$ Programa de Pós-Graduação em Engenharia e Gestão do Conhecimento, Universidade Federal de Santa Catarina, Campus Universitário, CP 476, CEP 88040-900, Florianópolis - SC, Brasil, E-mails: mau.capo@egc.ufsc.br; fapfialho@ gmail.com; leonardiadm@gmail.com; 1flopes@utfpr.edu.br; samuelfr@tre-sc.gov.br

2 Instituto de Pesquisas Sociais, Universidade Regional de Blumenau, Rua Antonio da Veiga, 140, CEP 89010-971, Blumenau - SC, Brasil, E-mail: wilhelm@furb.br
} 
pertinente, atual e aplicável, e deve atender às metas de desempenho das organizações. Sua importância pode ser verificada a partir da preocupação e do esforço cada vez maior das organizações em estabelecer critérios e métodos para garantir a efetiva gestão do conhecimento.

Um dos principais pilares da gestão do conhecimento é a adequada gestão do capital intelectual da organização. Ainda de acordo com Stankosky (2005), a gestão do capital intelectual tornou-se essencial como uma fonte de vantagem competitiva. Para os gestores de capital intelectual, é de fundamental importância o processo de transformação de recursos humanos em ativos intelectuais, que possam ser geridos como outros ativos da organização.

Para renovar e sustentar uma vantagem competitiva no atual ambiente de negócios, a gestão do capital intelectual deve ser feita no sentido de captar e utilizar todos os conhecimentos e competências dos seus colaboradores, entre as quais se destacam suas aptidões e competências gerenciais, com o intuito de atingir os objetivos estratégicos da organização.

Neste sentido, as ciências cognitivas, cujo foco é estudar o conhecimento em si e suas formas de representação, manipulação e armazenamento, têm muito a contribuir. Segundo Fialho (2001), um dos grandes desafios da psicologia cognitiva tem sido a construção das interpretações das situações cotidianas, como são construídas as representações mentais e como se dá a compreensão.

De modo a superar este desafio, os estudiosos das ciências cognitivas têm proposto diversas ferramentas no sentido de identificar modelos mentais, aptidões cerebrais, estilos cognitivos e/ou tipos psicológicos, que serão tratados dentro de um mesmo contexto, neste artigo. Estas ferramentas procuram representar aquilo que está contido no cérebro humano e que provoca determinados comportamentos e atitudes na realização das tarefas.

Uma destas ferramentas foi apresentada por William "Ned" Herrman (HERRMAN, 1990) que propôs a teoria da dominância cerebral, pela qual é possível identificar modelos de uso preferencial de aptidões cerebrais. Em seu modelo Herrman identifica quatro modelos de pensamento: analítico, sequencial, interpessoal e imaginativo. Com base nestes estudos, Miranda (1997) apresenta um modelo baseado na multipolaridade cerebral, destacando as diferentes capacidades e potencialidades da mente humana na realização de atividades cotidianas.

Baseado no modelo de aptidões proposto por Miranda (1997), a proposta deste artigo é identificar como este pode ser utilizado como apoio na identificação das competências gerenciais necessárias para fazer frente aos desafios da sociedade do conhecimento. Para Quinn et al. (2003), as competências gerenciais implicam tanto na detenção de um conhecimento quanto na capacidade comportamental de agir de maneira adequada. Para desenvolver determinadas competências é preciso não só apresentar conhecimento teórico como ter a oportunidade de praticá-los. Neste caso, quanto mais complexo for o nível de exigência que o cargo requer do profissional, mais aptidões lhe são exigidas.

Assim, a questão de pesquisa aqui tratada pode ser apresentada da seguinte forma: existe uma relação direta entre a função ocupada por um determinado indivíduo em nível gerencial de uma organização, suas aptidões cerebrais e as competências gerenciais requeridas pelo cargo? Para responder a esta pergunta, foi realizado um estudo com funcionários de nível gerencial tático operacional em uma empresa têxtil de médio porte no Estado de Santa Catarina. Este estudo identifica e analisa o perfil de aptidões cerebrais dos gerentes de acordo com o modelo proposto por Miranda (1997), relacionando-o com o perfil esperado para o cargo ocupado pelos gerentes, e com o modelo de competências gerenciais proposto por Quinn et al. (2003).

A importância deste tipo de avaliação é corroborada por Culp e Smith (2001) que destacam a importância da identificação dos modelos mentais para a melhoria da performance organizacional. Para os autores, entender os tipos psicológicos permite (p. 25): (a) obter uma descrição de como os indivíduos obtêm e tratam as informações; (b) identificar vulnerabilidades em uma equipe de projeto; (c) informar ao grupo como apresentar e comunicar informações aos colegas ou aos clientes; (d) entender as diferenças entre as pessoas no ambiente de trabalho; (e) obter informações sobre necessidades de treinamento nas equipes de trabalho; (f) demonstrar o valor de ter estilos diversos na equipe; (g) melhorar a solução de problemas e a tomada de decisão; (h) melhorar a eficácia na resolução de conflitos; (i) reduzir o nível de stress; (j) ajudar o grupo a ser mais eficaz em reuniões; (k) melhorar a produtividade associando pessoas a projetos de acordo com seu perfil ou estilo preferido; (1) auxiliar o grupo no cumprimento de prazos por meio de uma distribuição adequada de tarefas; (m) proporcionar o autoconhecimento e melhorar o relacionamento interpessoal com os colegas e clientes.

A importância de se relacionar as aptidões cerebrais com as competências organizacionais também é destacada por Eales-White (2005). Segundo ele, este conhecimento amplia a possibilidade de sucesso no desenvolvimento das competências individuais, alinhando-as com as competências organizacionais e trazendo, consequentemente, vantagens a longo prazo para o indivíduo e para a organização. Indo mais além, Sense (2007) destaca que conhecer os estilos cognitivos é um recurso importante para melhor entender e gerenciar equipes de projeto, permitindo 
aos indivíduos desenvolver suas competências no aprender a aprender.

Assim, com o intuito de relacionar as aptidões cerebrais com as competências gerenciais, este artigo está organizado da forma que segue: na seção dois, é apresentada a fundamentação teórica acerca das ciências cognitivas, destacando trabalhos que a relacionam com elementos da gestão das organizações, bem como é detalhado o modelo de aptidões cerebrais proposto por Miranda (1997). $\mathrm{Na}$ seção 3, é apresentada a fundamentação do modelo de competências gerenciais proposto por Quinn et al. (2003). Na seção 4, é apresentada a pesquisa, em uma abordagem descritiva quantitativa, bem como são analisados os resultados encontrados. Por fim, na seção 5, são apresentadas as conclusões do trabalho e possíveis direcionamentos para trabalhos futuros.

\section{Ciência cognitiva e \\ as aptidões cerebrais}

Gardner (1996) define a ciência cognitiva como um campo multidisciplinar, baseada em áreas como filosofia, neurociência, psicologia, computação, linguística e antropologia. Entretanto, novos autores têm ampliado cada vez mais este arcabouço conceitual, relacionando as ciências da cognição com outras áreas do conhecimento. Maturana e Varela (1997) defendem que a ciência da cognição tem diversas abordagens muitas vezes desconexas e que seu estudo reflete as particularidades da área que a estuda. Fialho (2001) as caracteriza como sendo transdisciplinar, pois a combinação de visões de diferentes áreas do conhecimento produz novas epistemes.

Para Thagard (1996), a hipótese central da Ciência Cognitiva é que o funcionamento da mente é mais bem entendido em termos de representações mentais e procedimentos computacionais que atuam sobre tais representações. As representações mentais são formas de representar internamente o mundo externo. As pessoas não captam o mundo exterior diretamente: elas constroem representações mentais internas dele.

As pesquisas para identificação de modelos mentais têm variado de nome ou de enfoque. Algumas são tratadas como identificação de estilos cognitivos, outras de tipos psicológicos e outras de dominância cerebral ou aptidões cerebrais. $\mathrm{O}$ fato é que todas têm o objetivo de procurar externalizar as representações de um estado de ações, portanto de um modelo mental.

Um dos trabalhos mais conhecidos nesta linha é o inventário tipológico desenvolvido por Myers-Briggs denominado MBTI (Myers-Briggs Type Indicator) (MYERS et al., 1998). Com base nos trabalhos do psicanalista Carl G. Jung, as autoras desenvolveram um instrumento com o propósito de identificar e inventariar os tipos psicológicos (funções e atitudes) predominantes em um determinado indivíduo.

A partir daí, diversos autores realizaram estudos relacionando os resultados do MBTI com o ambiente de trabalho ou escolar. Gardner e Martinko (1996) apresentaram um estudo bibliográfico, procurando identificar trabalhos que relacionassem tipos psicológicos do MBTI, com o comportamento gerencial. Também baseado no MBTI, Culp e Smith (2001) identificaram tipos psicológicos em diversos tipos de profissionais, tais como, engenheiros, corretores de seguros, consultores, entre outros, procurando identificar perfis e características comuns. Além disso, eles apresentaram problemas comuns no ambiente de trabalho que poderiam ser mais bem compreendidos e tratados ao se entender os tipos psicológicos.

Baseado no mesmo instrumento, Licht, Oliveira e Ventura (2007) apresentaram um estudo sobre tipos psicológicos de empreendedores, definindo o perfil tipológico de ocorrência mais comum entre eles. Em outro estudo utilizando os perfis tipológicos obtidos por meio do MBTI, Blass e Hackston (2008) procuraram identificar os tipos de personalidade dos líderes atuais, definir competências e habilidades necessárias aos líderes do futuro e discutir como os psicólogos e os gestores de pessoas nas organizações podem ajudar os líderes no desenvolvimento destas competências e habilidades.

Também usando resultados auferidos pelo MBTI, Sense (2007) destacou que, quando tornados públicos, os estilos cognitivos podem ser utilizados como um importante recurso para orientar o processo de aprendizagem (p. 39). Já Jennings e Disney (2006) apresentam uma provocação, questionando se o tipo psicológico tem influência no processo de construção do planejamento estratégico. Os autores criticam estudos anteriores que estabelecem perfis específicos para a seleção de pessoas que atuam em processos de planejamento estratégico e desmistificam o uso da ferramenta como solução para a formação de equipes.

Na mesma linha, Fox e Spence (1999) conduziram um estudo baseado em outra ferramenta, o Decision Style Inventory (DSI), procurando identificar estilos de decisão em gestores de projetos, concluindo, entretanto, sobre a não existência de um perfil estereotipado para estes profissionais, em função da diversidade de tarefas executadas por eles.

Já com uma visão diferenciada sobre as possibilidades geradas por estes instrumentos, Sabatier e Oppenheim (2001) usaram uma variação do MBTI - o IPTI (Integrated Psychological Type Indicator) - para identificar discriminações no ambiente de trabalho, sobretudo em relação às mulheres, em instituições financeiras da cidade de Londres. 
Também baseado em outra ferramenta, o Cognitive Style Index (CSI), Allinson, Armstrong e Hayes (2001), cruzaram o estilo cognitivo de líderes e subordinados, com foco na teoria de liderança LMX (Leader-Member Exchange Theory). $\mathrm{O}$ estudo identificou que a diferença de estilos cognitivos influencia o relacionamento entre líderes e subordinados, mas não revelou se esta diferença tem influência na performance para a organização.

Também baseado no CSI, Armstrong e Priola (2001) conduziram um estudo buscando identificar a influência dos estilos cognitivos em equipes de trabalho autogerenciáveis. Eles concluíram que grupos com características homogêneas obtêm, em geral, melhor performance.

Aritzeta, Senior e Swailes (2005) cruzaram dois outros instrumentos para avaliar a relação entre estilos cognitivos e os papéis desempenhados por membros de equipes. Os instrumentos utilizados foram o Team Role Self-Perception Inventory (TRSPI) e o Kirton's Adaption-Innovation Inventory (KAI). A pesquisa foi realizada com grupos de gestores e estudantes e destacou a importância de existirem pessoas com diferentes estilos e perfis em uma equipe.

Sem usar nenhuma ferramenta específica, Cools e Broeck (2008) apresentam um estudo qualitativo relacionando estilos cognitivos e comportamento gerencial. Nestes estudos os autores observaram que este relacionamento contribui para aumentar a consciência sobre o estilo gerencial, fundamental para o desenvolvimento intrapessoal e para a cooperação interpessoal.

Enfim, diversos são os exemplos de pesquisas que relacionam modelos mentais ao ambiente de trabalho, procurando identificar elementos que possam aumentar a performance organizacional, demonstrando a importância da presente pesquisa. Nem sempre, entretanto, esta relação tem sucesso, além de poder incorrer em armadilhas, como apontado por Culp e Smith (2001), que destacam o perigo de se formarem estereótipos, que podem criar barreiras ou pré-julgamentos quanto à competência de um indivíduo para realizar uma tarefa.

A partir desta perspectiva e cuidados em mente, será descrito, em detalhes, o modelo proposto por Miranda (1997) para a identificação de aptidões cerebrais.

\subsection{Modelo de multipolaridade cerebral}

Segundo Miranda (1997), os primeiros estudos sobre as aptidões cerebrais se concentraram em uma abordagem dualista do cérebro. $\mathrm{O}$ hemisfério direito abrangia as aptidões de raciocínio abstrato, conceitual e intuitivo, baseando-se em especulações, percepções e possibilidade. Já no hemisfério esquerdo estavam concentradas as aptidões como o raciocínio lógico, formal e analítico, baseados na razão e na lógica sequencial dos fatos.

Herrmann (1990) propôs a teoria da dominância cerebral apresentando a metáfora de subdivisão do cérebro em quatro quadrantes, sendo que cada um possui características e habilidades distintas: criativo, planejador, comunicativo e analítico. Com base nesta abordagem, foi desenvolvido o Herrmann Brain Dominant Instrument (HBDI), uma ferramenta de avaliação que quantifica o grau de dominância pessoal de cada um dos quadrantes. Segundo Herrmann (1996), por meio de análises estatísticas da aplicação do HBDI, é possível comprovar que as opções de carreira profissional e condutas pessoais são influenciadas pela dominância destas aptidões.

A partir dos estudos de Herrmann (1990), Miranda (1997) propôs um modelo baseado na multipolaridade cerebral, classificando as aptidões cerebrais em seis grupos distintos de acordo com suas características:

- corporais/viscerais (S): relacionadas com as capacidades fisiológicas, os sentidos, as habilidades mecânicas e motoras, sensórias, físico-orgânicas e atléticas e as características de espontaneidade e reações reflexivas;

- metafísicos/espirituais $(\mathrm{N})$ : relacionadas com o caráter espiritual no sentido de receber informações extrassensoriais, conhecer independentemente de análise e outros fatores subjetivos;

- preventivos/organizacionais (SO): relacionadas com a capacidade de desenvolver e operacionalizar ações de forma organizada e planejada;

- emotivos/relacionais (SE): relacionadas com a capacidade de socialização e comunicação;

- analíticos/factuais (NO): relacionadas com a capacidade analítica e de otimização racional;

- intuitivos/conceituais (NE): relacionadas com a capacidade de formulação de ideias e inovações.

Para Miranda (1997), os polos SO (PreventivoOrganizacional), SE (Emotivo-Relacional), NO (Analítico-Fatual) e NE (Intuitivo-Conceitual) podem ser codificados e desenvolvidos. Já os polos $\mathrm{S}$ (Corporal/Visceral) e N (Metafísico/Espiritual) não podem ser acionados ou controlados conscientemente. A Figura 1 apresenta uma síntese do modelo.

A Tabela 1 apresenta uma análise dos polos codificáveis de acordo com características que influenciam o comportamento humano, a aprendizagem, o trabalho e os descritivos pessoais.

Para Miranda (1997),

o exame e o conhecimento das diferentes aptidões cerebrais e de seu nível de dominância e de intensidade nos faculta a percepção dos diferentes 
tipos de demanda, no trabalho e no gerenciamento" (p. 128).

Neste contexto, está a importância de se avaliar a relação de seu modelo com as competências gerenciais.

\section{Competências gerenciais}

As competências são entendidas como combinações sinérgicas de conhecimentos, habilidades e atitudes, expressas pelo desempenho profissional em determinada função (competências individuais) em conjunto com a estratégia organizacional (competência organizacional) (CARBONE; BRANDÃO; LEITE, 2008).

Prahalad e Hamel (1990) definem a competência organizacional como sendo o conjunto de conhecimentos, habilidades, tecnologias, sistemas físicos, gerenciais e valores que geram diferencial competitivo para a organização.

Para que a competência organizacional possa ser atingida, uma série de fatores é requerida, entre eles as aptidões individuais e coletivas. Para Zarifian (2001),

a competência é assumida por um coletivo, mas depende de cada pessoa individualmente. O trabalho em equipe, em rede ou por projeto fornece um quadro e um referencial para a ação de cada pessoa e formaliza a convergência necessária das ações profissionais, mas cada pessoa singular torna-se importante em si mesma. (p. 97).

Portanto, a competência gerencial é um fator essencial que interliga as capacidades individuais com as organizacionais. Fleury e Fleury (2000) relatam ser um

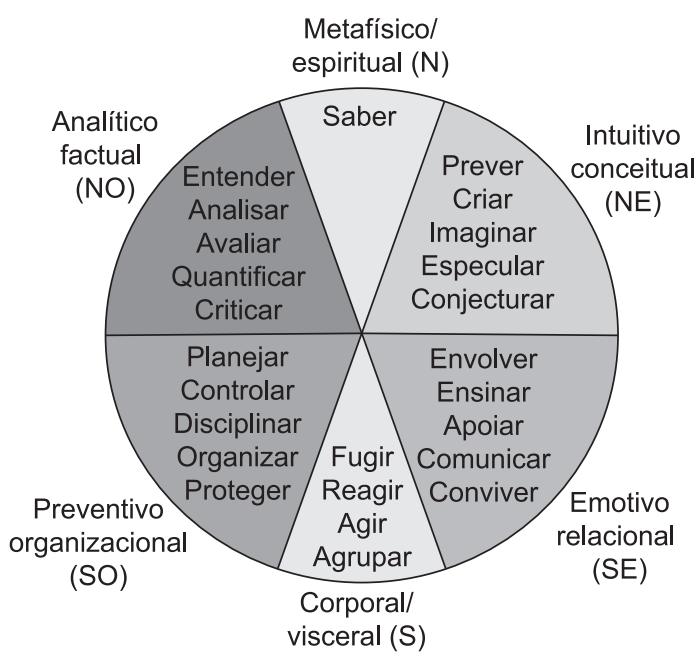

Figura 1. Modelo de multipolaridade cerebral de Miranda (1997). saber agir responsável reconhecido, que implica mobilizar, integrar, transferir conhecimentos, recursos, habilidades, que agreguem valor econômico à organização e valor social ao indivíduo.

Assim, a importância do desenvolvimento das competências gerenciais é indispensável na condução das equipes, tornando-as mais eficientes e competitivas.

A competência gerencial está associada ao nível de habilidades que suas tarefas exigem. Katz (apud MAXIMIANO, 2007) afirma que "habilidade é a capacidade de transformar conhecimento em ação e que resulta em um desempenho desejado". As habilidades podem ser:

- habilidades técnicas: relacionadas com o "fazer", ou seja, trabalhar com processos materiais ou objetivos físicos. Envolvem o uso de conhecimento especializado e facilidade na execução de técnicas relacionadas com o trabalho e com o processo de realização;

- habilidades humanas: relacionadas ao trabalho com pessoas. Envolvem o relacionamento interpessoal e grupal e a capacidade de comunicar, motivar, coordenar, liderar e resolver conflitos pessoais; e

- habilidades conceituais: relacionadas com o pensar. Envolvem a facilidade em trabalhar com ideias e conceitos, teorias e abstrações, e a visão da organização ou da unidade organizacional como um todo.

Katz salienta que, conforme o gerente sobe na hierarquia organizacional, a importância da competência técnica diminui, evidenciando mais as habilidades conceituais. As habilidades humanas devem ser igualmente utilizadas em todos os níveis (Figura 2).

Os diversos ambientes organizacionais, por terem objetivos e características específicos, requerem habilidades próprias para aquele determinado setor,

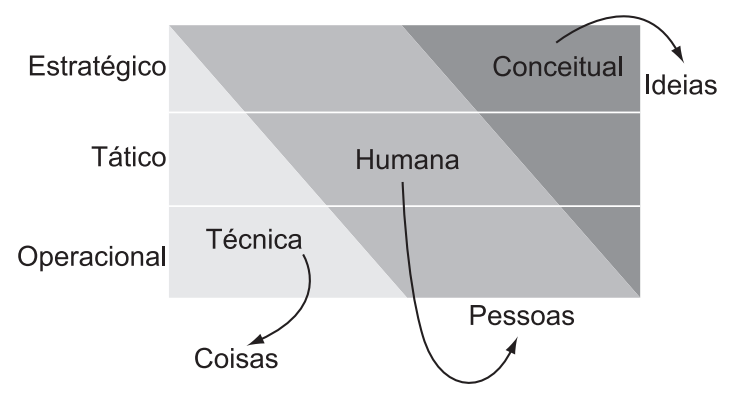

Figura 2. Modelo de habilidades gerenciais de Katz. 
e os papéis gerenciais podem se alterar, conforme o crescimento que o cargo exigir. Assim, por exemplo, um gerente que atuaria num nível técnico, poderia apresentar um papel mais de controle, monitoração; já um gerente de nível conceitual, apresentaria um papel inovador ou negociador. Em nível humano, o de facilitador.

Quinn et al. (2003) afirmam, entretanto, que uma competência não está associada apenas na aquisição de determinadas habilidades, mas implica na detenção tanto de um conhecimento quanto da capacidade comportamental de agir de maneira adequada. Para desenvolver determinadas competências é preciso não só apresentar o conhecimento teórico como ter a oportunidade de praticá-las. Assim, ele apresenta quatro modelos organizacionais, tendo cada um deles dois papéis gerenciais, com as características apresentadas na Tabela 2.

A Figura 3 apresenta um complemento para a Tabela 2, destacando três competências gerenciais para cada um dos oito papéis gerenciais propostos por Quinn et al. (2003). É importante destacar que cada papel é complementar àqueles que lhe fazem fronteira e contrasta com aqueles com os quais se opõem. Por exemplo, o papel facilitador é complementar ao papel de mentor e monitor e contrasta com o papel de produtor. No entanto, um gerente pode apresentar vários estilos ao mesmo tempo ainda que contrastantes. Por exemplo, pode ter competências do perfil inovador (Modelo Sistemas Aberto) e do perfil

Tabela 1. Características dos polos cerebrais (MIRANDA, 1997).

\begin{tabular}{|c|c|c|c|c|}
\hline & $\begin{array}{c}\text { Intuitivo } \\
\text { conceitual } \\
\text { (NE) }\end{array}$ & $\begin{array}{l}\text { Emotivo } \\
\text { relacional } \\
(\mathrm{SE}) \\
\end{array}$ & $\begin{array}{c}\text { Preventivo } \\
\text { organizacional } \\
(\mathrm{SO})\end{array}$ & $\begin{array}{l}\text { Analítico } \\
\text { factual } \\
\text { (NO) }\end{array}$ \\
\hline $\begin{array}{l}\text { Características no } \\
\text { comportamento } \\
\text { humano }\end{array}$ & $\begin{array}{l}\text { Imagina, especula, } \\
\text { assume riscos e } \\
\text { geralmente não se } \\
\text { restringe às regras } \\
\text { estabelecidas. } \\
\text { Gosta de surpresas } \\
\text { e é extremamente } \\
\text { curioso. }\end{array}$ & $\begin{array}{l}\text { Sensível em relação } \\
\text { às outras pessoas, } \\
\text { gosta e tem facilidade } \\
\text { em ensinar, bem } \\
\text { como fazer contatos } \\
\text { e amizades. É } \\
\text { emocional e falante. }\end{array}$ & $\begin{array}{l}\text { Prevenido em } \\
\text { todos os sentidos, } \\
\text { estabelece } \\
\text { procedimentos para } \\
\text { ação. O planejamento } \\
\text { lhe traz segurança. }\end{array}$ & $\begin{array}{l}\text { Analisa e quantifica } \\
\text { os fatos de forma } \\
\text { detalhada. É lógico, } \\
\text { racional, crítico e } \\
\text { sabe como as coisas } \\
\text { funcionam nos } \\
\text { mínimos detalhes. }\end{array}$ \\
\hline $\begin{array}{l}\text { Características na } \\
\text { aprendizagem }\end{array}$ & $\begin{array}{c}\text { Prefere a intuição, } \\
\text { utilizando a } \\
\text { imaginação e } \\
\text { formulando sínteses; } \\
\text { prefere materiais } \\
\text { visuais e exemplos } \\
\text { metafóricos, o } \\
\text { clima informal e } \\
\text { flexibilidade. }\end{array}$ & $\begin{array}{l}\text { Prefere ouvir e } \\
\text { compartilhar; } \\
\text { confia na intuição } \\
\text { e envolvimento } \\
\text { emocional; prefere as } \\
\text { discussões de casos } \\
\text { voltados para pessoas } \\
\text { e trabalho em grupo. }\end{array}$ & $\begin{array}{l}\text { Prefere conteúdo e } \\
\text { pauta estruturados } \\
\text { e organizados; } \\
\text { prefere a discussão } \\
\text { de casos mediada } \\
\text { e atividades bem } \\
\text { planejadas; valoriza } \\
\text { métodos tradicionais } \\
\text { comprovados. }\end{array}$ & $\begin{array}{c}\text { Prefere obter e } \\
\text { quantificar fatos, } \\
\text { aplicar análises e } \\
\text { lógica, elaborar } \\
\text { teorias e desenvolver } \\
\text { o pensamento } \\
\text { crítico; prefere dados } \\
\text { técnicos e fontes de } \\
\text { expertise. }\end{array}$ \\
\hline $\begin{array}{l}\text { Características no } \\
\text { trabalho }\end{array}$ & $\begin{array}{l}\text { Reconhece novas } \\
\text { possibilidades, } \\
\text { integra bem as ideias } \\
\text { e desafia normas } \\
\text { e políticas rígidas. } \\
\text { Sintetiza elementos } \\
\text { diferentes e encontra } \\
\text { soluções inovadoras } \\
\text { para os problemas. } \\
\text { Visualiza com } \\
\text { facilidade mudanças } \\
\text { futuras. }\end{array}$ & $\begin{array}{c}\text { Reconhece } \\
\text { dificuldades } \\
\text { interpessoais } \\
\text { e percebe os } \\
\text { sentimentos. Sabe } \\
\text { persuadir, conciliar } \\
\text { e compartilhar } \\
\text { experiências; } \\
\text { considera valores } \\
\text { pessoais e tem } \\
\text { facilidade em } \\
\text { compreender } \\
\text { elementos } \\
\text { emocionais. }\end{array}$ & $\begin{array}{l}\text { Encontra falhas } \\
\text { não percebidas, } \\
\text { aborda problemas } \\
\text { de forma prática e é } \\
\text { firme nas posições } \\
\text { que toma. Tem } \\
\text { facilidade para lidar } \\
\text { com documentos e } \\
\text { contratos. Planeja } \\
\text { com detalhes, } \\
\text { sabendo articular } \\
\text { muito bem seus } \\
\text { planos. }\end{array}$ & $\begin{array}{l}\text { Gosta de pesquisar } \\
\text { dados, analisar } \\
\text { questões e discutir } \\
\text { de forma racional. } \\
\text { Apresenta boa análise } \\
\text { crítica, elabora } \\
\text { teorias e resolve } \\
\text { problemas pela } \\
\text { lógica. Individualista, } \\
\text { gosta de trabalhar } \\
\text { com números, dados } \\
\text { e estatísticas. }\end{array}$ \\
\hline Descritivos & $\begin{array}{c}\text { Idealista, impetuoso, } \\
\text { imprevisível, } \\
\text { inconformado e } \\
\text { mente aberta. }\end{array}$ & $\begin{array}{l}\text { Emocional, empático, } \\
\text { humanista, instintivo } \\
\text { e entusiasta. }\end{array}$ & $\begin{array}{c}\text { Previsível, } \\
\text { tradicional, } \\
\text { organizado, reservado } \\
\text { e pontual. }\end{array}$ & $\begin{array}{c}\text { Individualista, crítico, } \\
\text { decidido, analítico e } \\
\text { bem informado. }\end{array}$ \\
\hline
\end{tabular}


Tabela 2. Modelo Organizacional (QUINN et al., 2003).

\begin{tabular}{|c|c|c|c|c|c|}
\hline Modelo & Papéis & Objetivos & Crenças & $\begin{array}{l}\text { Critérios de } \\
\text { eficácia }\end{array}$ & $\begin{array}{c}\text { Características do } \\
\text { gerente }\end{array}$ \\
\hline $\begin{array}{l}\text { Sistemas } \\
\text { abertos }\end{array}$ & $\begin{array}{l}\text { Inovador e } \\
\text { negociador }\end{array}$ & $\begin{array}{l}\text { Inovação e o } \\
\text { gerenciamento da } \\
\text { mudança }\end{array}$ & $\begin{array}{l}\text { Adaptação e } \\
\text { inovação contínuas } \\
\text { promovem melhores } \\
\text { resultados }\end{array}$ & $\begin{array}{l}\text { Adaptabilidade e } \\
\text { apoio externo }\end{array}$ & $\begin{array}{l}\text { Inovador criativo e } \\
\text { um negociador ágil }\end{array}$ \\
\hline $\begin{array}{l}\text { Metas } \\
\text { racionais }\end{array}$ & $\begin{array}{l}\text { Diretor e } \\
\text { produtor }\end{array}$ & $\begin{array}{l}\text { Maximização dos } \\
\text { lucros }\end{array}$ & $\begin{array}{l}\text { Direção clara } \\
\text { acarreta resultados } \\
\text { produtivos }\end{array}$ & $\begin{array}{l}\text { Produtividade e } \\
\text { lucro }\end{array}$ & $\begin{array}{l}\text { Decisivo e um } \\
\text { produtor pragmático }\end{array}$ \\
\hline $\begin{array}{l}\text { Processos } \\
\text { internos }\end{array}$ & $\begin{array}{l}\text { Monitor e } \\
\text { coordenador }\end{array}$ & $\begin{array}{l}\text { Eficiência do fluxo de } \\
\text { trabalho }\end{array}$ & $\begin{array}{l}\text { Rotina e as } \\
\text { decisões tomadas } \\
\text { com base em } \\
\text { regras, estruturas e } \\
\text { tradições promovem } \\
\text { estabilidade }\end{array}$ & $\begin{array}{l}\text { Estabilidade e } \\
\text { continuidade }\end{array}$ & $\begin{array}{l}\text { Monitor inflexível } \\
\text { e um coordenador } \\
\text { pragmático }\end{array}$ \\
\hline $\begin{array}{l}\text { Relações } \\
\text { humanas }\end{array}$ & $\begin{array}{l}\text { Mentor e } \\
\text { facilitador }\end{array}$ & $\begin{array}{l}\text { Envolvimento e } \\
\text { comprometimento da } \\
\text { equipe }\end{array}$ & $\begin{array}{l}\text { Participação, } \\
\text { resolução de } \\
\text { conflitos e } \\
\text { construção de } \\
\text { consenso }\end{array}$ & $\begin{array}{l}\text { Compromisso e } \\
\text { coesão }\end{array}$ & $\begin{array}{l}\text { Mentor empático } \\
\text { e um facilitador } \\
\text { centrado em pessoas }\end{array}$ \\
\hline
\end{tabular}

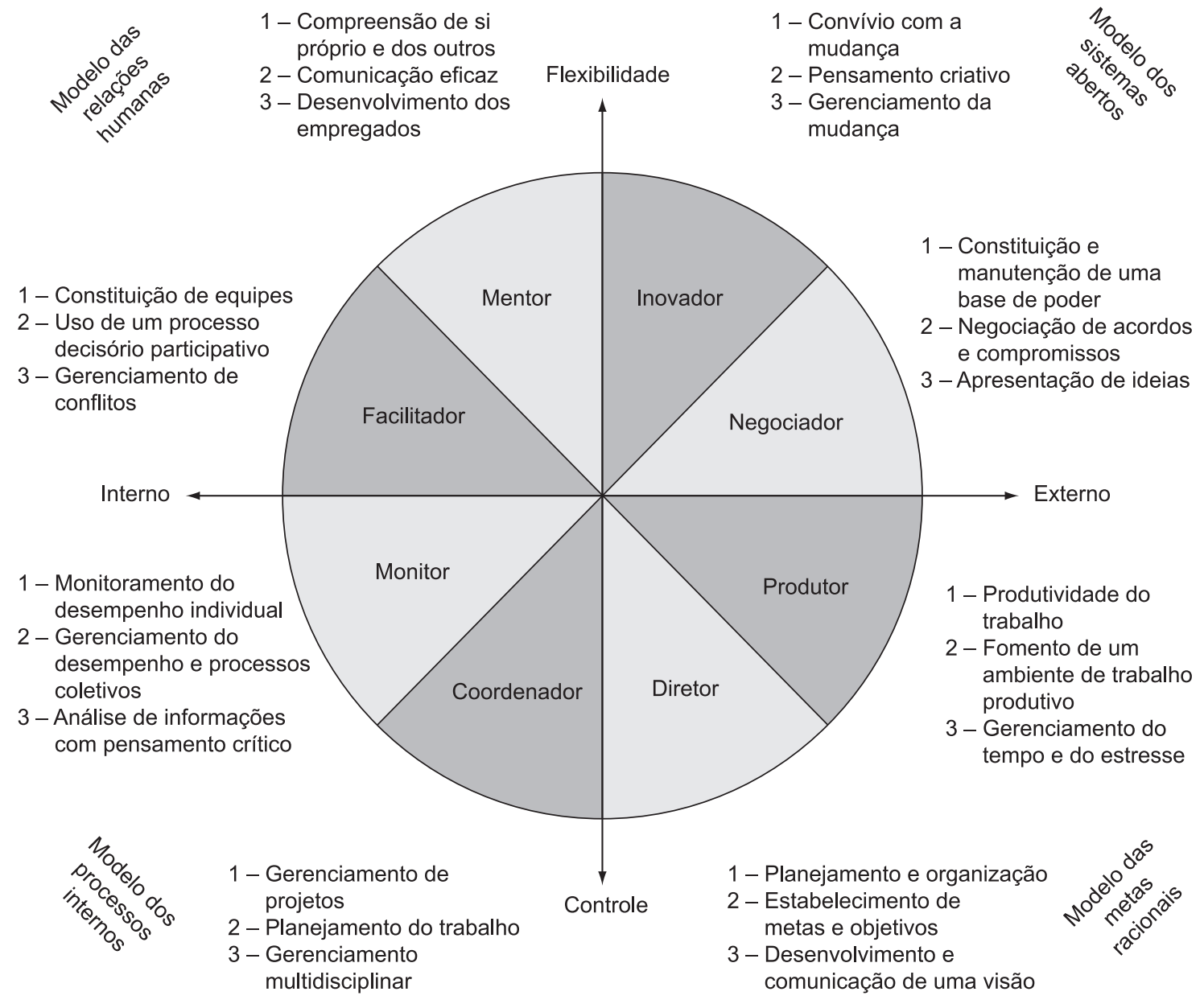

Figura 3. Papéis e competências gerenciais (QUINN et al., 2003). 
coordenador (Modelo dos Processos Internos). Os perfis se adaptam dependendo das aptidões mentais e capacidades intrínsecas de cada pessoa. Ressalta-se, ainda, que o eixo vertical trata da visão do controle e da flexibilidade e o horizontal trata da visão do interno e externo à organização.

Ireland (2006) faz uma importante complementação à proposta de Quinn et al. (2003), quando destaca que as competências pessoais consistem naqueles atributos que uma pessoa apresenta na gestão de si próprio, conduzindo os seus negócios, e, sobretudo, controlando suas ações. Competências pessoais estabelecem as bases para interações com os outros, tanto em um ambiente empresarial como social.

Tais competências são mais bem aproveitadas, na organização, quando existe uma gestão que favoreça um ambiente propício para aplicá-las. Cabe aos gerentes esta responsabilidade de alavancar e direcionar esforços, conduzindo as diversas funções existentes ao cumprimento dos objetivos organizacionais.

Neste sentido, associar competências gerenciais com aptidões cerebrais pode ser uma ferramenta para auxiliar os gestores no processo de gestão do capital intelectual, visando identificar os perfis exigidos para determinadas funções, facilitando o processo de recrutamento e seleção de pessoas, agregando, assim, vantagens competitivas à organização. Esta visão é a base da pesquisa que será apresentada a seguir.

\section{Relação entre aptidões cerebrais e competências gerenciais}

A partir do levantamento bibliográfico apresentado anteriormente foi realizada uma pesquisa descritiva no sentido de tentar relacionar o modelo de multipolaridade cerebral e as competências gerenciais. Para isto, foram utilizados dados coletados de funcionários de nível gerencial tático operacional em uma empresa têxtil de médio porte no Estado de Santa Catarina. A seguir serão apresentadas as etapas seguidas durante a pesquisa, já incluindo os procedimentos executados em cada uma delas.

\subsection{Coleta de dados}

A primeira etapa da pesquisa foi a coleta de dados realizada com 127 gestores de nível tático operacional, incluindo gerentes, supervisores e inspetores de dez setores da empresa em questão.

A coleta dos dados foi realizada com a aplicação do questionário proposto por Miranda (1997, p. 105-108). O questionário é composto de 8 questões, com 16 alternativas cada, sendo que o entrevistado deve escolher 4 respostas para cada questão, obtendo-se um conjunto total de 32 respostas. $\mathrm{O}$ anexo 1 apresenta exemplos de questões propostas no questionário.
A aplicação do questionário conduz a uma sistematização também proposta por Miranda (1997, p. 109-110), que fornece o perfil de aptidões cerebrais dominantes de cada entrevistado. A Figura 4 apresenta o exemplo de sistematização dos dados do questionário para uma pessoa.

Pela figura, observa-se que a pessoa em questão tinha um perfil predominantemente voltado ao polo lógico-racional (34\%), mas também com um perfil elevado no polo intuitivo-racional (28\%), em detrimento dos polos preventivo-organizacional (20\%) e emotivo-relacional (18\%). Destaca-se que a soma de todos os perfis deve ser igual a $100 \%$.

Segundo Miranda (1997, p. 110), resultados acima de 50\% definem aptidões de alta dominância e abaixo de $20 \%$ definem aptidões de baixa dominância. Entretanto, a experiência dos autores deste artigo com mais de mil diagnósticos realizados, demonstram que valores acima de $50 \%$ têm pouca frequência. No caso desta amostra, por exemplo, apenas um indivíduo teve dominância acima de $50 \%$, tendo ocorrido no polo SE. Assim, para efeito de análise neste trabalho, será considerado dominante o polo com maior valor percentual alcançado pelo indivíduo.

É importante destacar que no momento da aplicação do questionário, não havia a intenção de relacionar os resultados obtidos com as competências gerenciais, mas apenas traçar o perfil de aptidões de cada gestor. A proposta de se fazer esta relação surgiu depois de se acumular um grande número de informações sobre os indivíduos, as quais poderiam ser utilizadas como fonte de conhecimento para a empresa.

\subsection{Formulação das hipóteses}

O conjunto de dados obtidos no trabalho realizado no item anterior levou os pesquisadores a refletirem sobre se haveria relação entre o perfil de aptidões cerebrais dos entrevistados e as competências gerenciais requeridas na execução de sua tarefa. É importante

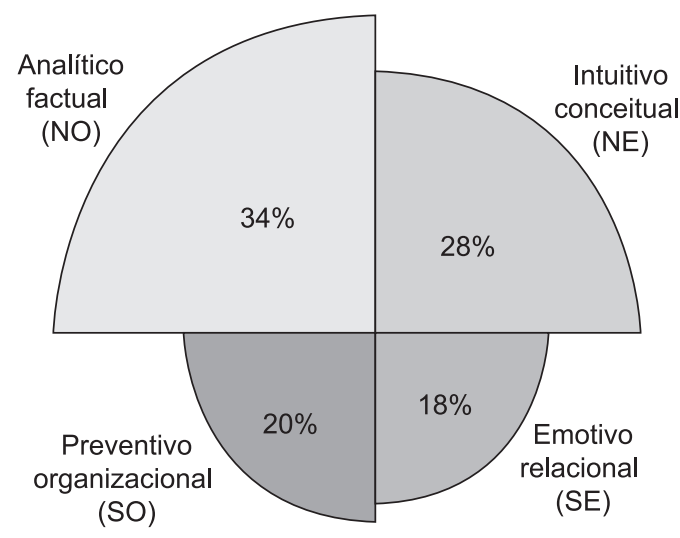

Figura 4. Perfil individual de aptidões cerebrais dominantes. 
ressaltar que está se tratando, principalmente, de competências técnicas e humanas, pois se trata de gerências de nível médio.

Deste modo as hipóteses formuladas para o trabalho foram os seguintes:

- os gerentes que lidam com processos criativos, cujas competências estão relacionadas ao modelo de sistemas abertos, têm suas aptidões dominantes em nível conceitual (polo NE);

- os gerentes que lidam com processos comunicativos, cujas competências estão relacionadas ao modelo das relações humanas, têm suas aptidões dominantes em nível relacional (polo SE);

- os gerentes que lidam com processos produtivos ou que requeiram organização/sistematização, cujas competências estão relacionadas ao modelo de processos internos, têm suas aptidões dominantes em nível organizacional (polo SO);

- os gerentes que lidam com processos analíticos, cujas competências estão relacionadas ao modelo de metas racionais, têm suas aptidões dominantes em nível lógico (polo NO);

- todos os gerentes têm aptidões dominantes no polo SE (emotivo-relacional), pois sua atividade pressupõe habilidades de relacionamento interpessoal, característica deste polo.

\subsection{Tabulação dos dados}

O passo seguinte foi tabular os dados por meio da sistematização dos questionários de acordo com a proposta de Miranda (1997, p. 109-110). Assim, para cada funcionário, foi definido seu perfil de aptidões de acordo com os quatro polos (NE, SE, NO, SO).

A partir dos dados individuais, os funcionários foram agrupados por setor da empresa, de modo a se determinar um perfil médio de aptidões dominantes por setor. A análise foi realizada a partir do cálculo da média e do desvio padrão. Também foi realizada a análise da variância (ANOVA) para cada setor, de modo a avaliar se as diferenças observadas para as médias dos quatro polos são significativas. Os valores calculados para a estatística F, bem como os valores críticos estão apresentados na Tabela 3.

Pela tabela, é possível verificar o número de entrevistados por setor, bem como os valores de média e desvio padrão obtidos em cada polo, a partir dos diagnósticos realizados. Os valores em negrito indicam o estilo de aptidão cerebral dominante (com maior média) nos entrevistados que atuam no setor em questão. A apresentação dos setores está agrupada por valores de maior média, para facilitar a análise frente às hipóteses definidas para a pesquisa. Por exemplo, Mercado e Recursos Humanos estão apresentados juntos, pois ambos tiveram a maior média no polo SE.

Tabela 3. Perfil de aptidões cerebrais dominantes por setor.

\begin{tabular}{|c|c|c|c|c|c|c|c|c|c|c|c|}
\hline \multirow[t]{2}{*}{ Setor } & \multirow[t]{2}{*}{$\begin{array}{c}\text { Número de } \\
\text { entrevistados }\end{array}$} & \multicolumn{2}{|c|}{$\begin{array}{c}\text { Intuitivo } \\
\text { conceitual } \\
\text { (NE) }\end{array}$} & \multicolumn{2}{|c|}{$\begin{array}{l}\text { Emotivo } \\
\text { relacional } \\
\quad(\mathrm{SE})\end{array}$} & \multicolumn{2}{|c|}{$\begin{array}{c}\text { Preventivo } \\
\text { organizacional } \\
(\mathrm{SO})\end{array}$} & \multicolumn{2}{|c|}{$\begin{array}{l}\text { Analítico } \\
\text { factual } \\
\text { (NO) }\end{array}$} & \multicolumn{2}{|c|}{ ANOVA } \\
\hline & & Média & DP & Média & DP & Média & DP & Média & DP & $\mathbf{F}$ & F-crít \\
\hline $\begin{array}{l}\text { Desenvolvimento } \\
\text { de Produtos }\end{array}$ & 6 & 0,33 & 0,09 & 0,22 & 0,05 & 0,26 & 0,10 & 0,19 & 0,04 & 3,745 & 3,098 \\
\hline Mercado & 36 & 0,27 & 0,09 & 0,28 & 0,10 & 0,26 & 0,09 & 0,19 & 0,09 & 6,073 & 2,669 \\
\hline $\begin{array}{l}\text { Recursos } \\
\text { Humanos }\end{array}$ & 7 & 0,22 & 0,08 & 0,32 & 0,07 & 0,30 & 0,08 & 0,16 & 0,04 & 6,336 & 2,704 \\
\hline Materiais & 6 & 0,16 & 0,06 & 0,30 & 0,07 & 0,31 & 0,10 & 0,23 & 0,13 & 3,714 & 3,098 \\
\hline $\begin{array}{l}\text { Plan. e Cont. da } \\
\text { Produção (PCP) }\end{array}$ & 7 & 0,21 & 0,05 & 0,30 & 0,13 & 0,31 & 0,06 & 0,19 & 0,11 & 3,013 & 3,008 \\
\hline Produção & 33 & 0,21 & 0,06 & 0,28 & 0,07 & 0,29 & 0,09 & 0,22 & 0,10 & 9,519 & 2,675 \\
\hline Qualidade & 7 & 0,24 & 0,04 & 0,22 & 0,08 & 0,29 & 0,09 & 0,25 & 0,10 & 0,767 & 3,009 \\
\hline $\begin{array}{l}\text { Segurança do } \\
\text { Trabalho }\end{array}$ & 7 & 0,24 & 0,09 & 0,29 & 0,08 & 0,33 & 0,11 & 0,15 & 0,09 & 4,869 & 3,009 \\
\hline Financeiro & 14 & 0,21 & 0,08 & 0,22 & 0,08 & 0,28 & 0,08 & 0,29 & 0,10 & 3,600 & 2,783 \\
\hline $\begin{array}{l}\text { Tecnologia da } \\
\text { Informação }\end{array}$ & 4 & 0,17 & 0,07 & 0,25 & 0,06 & 0,28 & 0,03 & 0,30 & 0,09 & 2,809 & 3,490 \\
\hline Média Geral & & 0,23 & 0,08 & 0,27 & 0,09 & 0,29 & 0,09 & 0,21 & 0,10 & & \\
\hline
\end{tabular}


Também pela tabela, é possível verificar que apenas os setores de Qualidade e Tecnologia da Informação não forneceram resultados que permitissem afirmar que as diferenças observadas entre os polos são significativas, pois nestes casos a ANOVA apontou um valor de $\mathrm{F}$ abaixo do F-crítico. Os demais resultados permitiram fazer algumas análises, que serão apresentadas na próxima seção.

\subsection{Interpretação dos resultados}

A próxima etapa foi interpretar os resultados. A seguir serão apresentadas as análises a partir de cada hipótese formulada.

Hipótese 1: os gerentes que lidam com processos criativos, cujas competências estão relacionadas ao modelo de sistemas abertos, têm suas aptidões dominantes em nível conceitual (polo NE).

O único setor com predominância do perfil intuitivoconceitual (polo NE) foi o de Desenvolvimento de Produtos que teve 6 entrevistados. O perfil intuitivoconceitual teve média de $33 \%$ e desvio padrão de 9 pontos, com uma grande vantagem (sete pontos percentuais) sobre o perfil preventivo-organizacional (26\%), que vem logo a seguir. De fato, as competências exigidas para este setor estão relacionadas ao modelo de sistemas abertos, pois este é um local da organização que necessita de líderes inovadores, uma vez que trata eminentemente de criação, gerenciamento de mudança e negociação, característicos da competência de líderes inovadores e negociadores. Sendo assim, o resultado permite aceitar a hipótese formulada.

Hipótese 2: os gerentes que lidam com processos comunicativos, cujas competências estão relacionadas ao modelo das relações humanas, têm suas aptidões dominantes em nivel relacional (polo SE).

Dois setores tiveram predominância do perfil emotivo-relacional: Mercado (36 entrevistados) e Recursos Humanos (7 entrevistados). O setor de Mercado foi o de maior equilíbrio com 3 perfis muito próximos: emotivo-relacional (polo SE: 28\%), intuitivoconceitual (NE: 27\%) e preventivo-organizacional (SO; 26\%). O desvio padrão, entretanto, reafirma a predominância do perfil emotivo- relacional (polo $\mathrm{SE}$ ). De fato, este é o setor de análise mais complexa, pois as competências exigidas são múltiplas. Contudo, pode-se afirmar que elas envolvem, sobretudo, o relacionamento interpessoal, a comunicação eficaz e o trabalho em equipe, característicos do modelo de Relações Humanas. Também as negociações e as ideias, característicos do polo NE, são fundamentais para os que trabalham neste setor, particularmente porque a empresa estudada atua no mercado nacional e internacional. Ainda no setor de Mercado, o resultado do preventivo-organizacional (polo SO), tão próximo aos demais, não era esperado, pois não deveria se tratar de um perfil fundamental para este setor.
No setor de Recursos Humanos há a dominância mais significativa do perfil emotivo-relacional (polo SE: $32 \%$ ), seguido pelo perfil preventivo-organizacional (SO: 30\%), inclusive com forte predominância destes sobre os outros perfis.. De fato, as competências exigidas para este setor estão relacionadas ao modelo de relações humanas uma vez que é nele que se concentram as atividades de comunicação, desenvolvimento e treinamento, e gerenciamento de conflitos. Por outro lado, neste setor também não era esperado um resultado médio tão elevado (30\%) para o perfil preventivo-organizacional (polo $\mathrm{SO})$. As médias altas para este perfil, tanto no setor de Mercado quanto no setor de Recursos Humanos, serão analisados em conjunto com a hipótese 5 .

De qualquer modo, o fato do perfil dos gerentes destes setores serem predominantes no polo SE, atende à hipótese aqui estabelecida.

Hipótese 3: os gerentes que lidam com processos produtivos ou que requeiram organização/ sistematização, cujas competências estão relacionadas ao modelo de processos internos, têm suas aptidões dominantes em nível organizacional (polo SO).

Cinco setores apresentaram dominância no polo preventivo-organizacional (polo $\mathrm{SO}$ ): Materiais (6 entrevistados), Planejamento e Controle da Produção (7), Produção (33), Segurança no Trabalho (7) e Qualidade (7). Os quatro primeiros setores citados têm perfis muito semelhantes, com predominância do preventivo-organizacional, seguido de forma muito próxima do emotivo-relacional. Isto dificulta, inclusive, o estabelecimento da dominância de um perfil sobre o outro, principalmente se analisado em conjunto com o desvio padrão. A exceção é o setor de Segurança no Trabalho que tem uma vantagem de 4 pontos percentuais de um perfil sobre o outro. De qualquer modo ao cruzar os resultados alcançados no perfil de aptidões com as competências exigidas no modelo de processos internos, é possível verificar convergências, pois nestes setores a eficiência e a rotina são a base para a gestão do desempenho individual e dos processos. O fato do perfil emotivo-relacional estar próximo ao preventivo-organizacional será avaliado na hipótese 5 .

O setor de Qualidade também teve predominância do perfil preventivo-organizacional (29\%), mas foi seguido pelo perfil analítico-factual (25\%). Neste setor, de fato são requeridas as competências exigidas por estes perfis, com muita organização e controle, além da necessidade de se trabalhar com análises visando a resolução de problemas, o que mostra aderência com os modelos de Processos Internos e Metas Racionais. Um resultado inesperado foi o apresentado pelo perfil intuitivo-conceitual (24\%), mesmo com um desvio padrão pequeno (4\%), por não tratar-se de um perfil comum neste tipo de setor. 
A partir desta análise, a inserção dos setores de Materiais, Planejamento e Controle da Produção, Produção e Segurança no Trabalho parece adequada à hipótese em questão. Já quanto ao setor de Qualidade, o ideal seria buscar uma amostra mais representativa.

Hipótese 4: os gerentes que lidam com processos analíticos, cujas competências estão relacionadas ao modelo de metas racionais, têm suas aptidões dominantes em nível lógico (polo NO).

Dois setores tiveram predominância do perfil analítico-factual: o Financeiro (14 entrevistados) e a Tecnologia da Informação (4 entrevistados). O setor Financeiro teve 29\% neste perfil seguido muito próximo (diferença de 1 ponto percentual) pelo perfil preventivo-organizacional (28\%). Já o setor de Tecnologia da Informação atingiu a maior média do perfil analítico-factual (30\%), seguido também pelo preventivo-organizacional (28\%).

Os resultados apresentados parecem coerentes, pois, de fato, o setor Financeiro, que no caso da empresa estudada inclui contabilidade e custos, lida predominantemente com números que requerem análises, concentração e raciocínio. Também o setor de Tecnologia da Informação lida, sobretudo com métodos, modelos, metodologias e técnicas que requerem análise, concentração e raciocínio lógico.

De qualquer modo, ambos os setores requerem as competências do modelo de Metas Racionais, pois são setores fortemente focados em estabelecer e buscar resultados efetivos para a organização, com controle e visão externa. Entretanto, não se pode afirmar que o setor de Tecnologia da Informação atenda à hipótese em questão em função dos resultados do teste ANOVA, exigindo-se, portanto, a busca de uma amostra mais representativa.

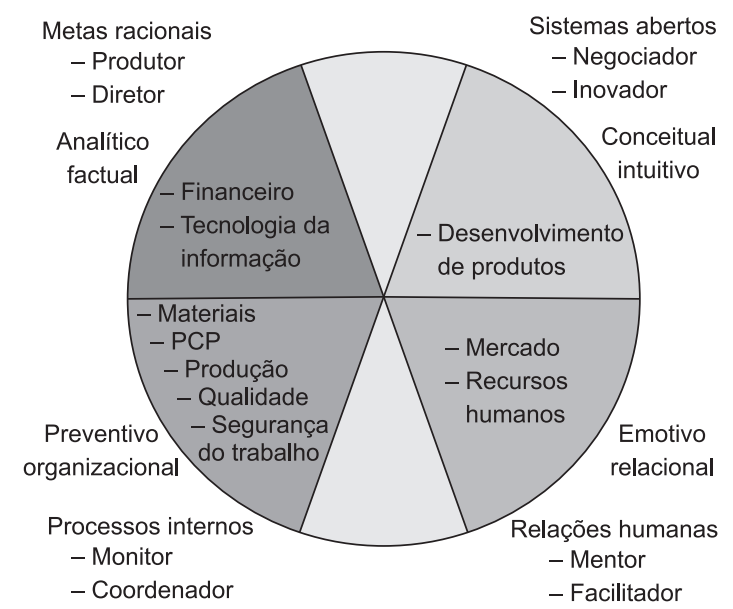

Figura 5. Resultado do perfil dominante por setor, relacionado com Miranda (1997) e Quinn et al. (2003).
Destaca-se o fato de que ambos tiveram como segunda média o perfil preventivo-organizacional. De fato, são setores também totalmente compatíveis com o modelo de Processos Internos, pois lidam com métodos e técnicas que requerem planejamento e organização.

Com base na análise dos resultados e nas hipóteses 1 a 4, a Figura 5 apresenta uma síntese da distribuição de dominância, relacionando os resultados obtidos em cada setor com os perfis propostos por Miranda (1997) e Quinn et al. (2003). Destaca-se que na figura estão invertidas as posições do Modelo de Metas Racionais e do Modelo de Relações Humanas de Quinn et al. (2003), em relação ao modelo apresentado na Figura 3. Esta inversão foi necessária para se obter uma representação mais próxima ao modelo de Miranda (1997). A figura apresenta ainda os papéis dos gerentes identificados para cada setor, de acordo com o seu respectivo modelo.

Hipótese 5: todos os gerentes têm aptidões dominantes no polo SE (emotivo-relacional), pois sua atividade pressupõe habilidades de relacionamento interpessoal, características deste polo.

A partir dos resultados alcançados, esta hipótese não foi comprovada. Pelos dados apresentados, o resultado médio do perfil foi de $27 \%$, com desvio padrão de $9 \%$. Avaliando os dados por setor, observa-se que os setores de Desenvolvimento de Produtos, Qualidade e Financeiro tiveram média de $22 \%$ neste perfil, com desvio padrão variando entre $5 \%$ e $8 \%$. Isto indica que nestes setores há uma baixa dominância das habilidades compatíveis com o polo SE. Este resultado pode ser fonte de problemas para a organização, uma vez que, de acordo com o modelo de Katz, as habilidades humanas são fundamentais para aqueles que ocupam cargos de gestão na organização.

Por outro lado, o perfil preventivo-organizacional (polo SO) teve a maior média (29\%), sempre com valores acima de $25 \%$ em todos os setores, e com desvio padrão de $9 \%$, demonstrando que não há dominância baixa (abaixo de 20\%) neste perfil. Isto indica que em todos os setores, os gerentes têm preparo técnico e a explicação pode estar no fato de que, como são gestores de nível tático operacional, provavelmente eles ainda estão fortemente focados em organização e controle. Assim, na maioria dos setores a orientação parece estar fortemente direcionada para a tarefa, muito mais do que para as pessoas.

Outra análise obtida a partir dos resultados alcançados e não avaliada em nenhuma das hipóteses definidas na pesquisa diz respeito à dominância média dos estilos inferiores (preventivo-organizacional: 29\% e emotivo-relacional: $27 \%$ ), em detrimento dos estilos superiores (intuitivo-conceitual: $23 \%$ e analítico-factual: 21\%). De acordo com Miranda (1997, p. 86), os perfis superiores estão mais relacionados ao fazer e os estilos superiores estão mais relacionados 
ao pensar. Assim, este resultado demonstra que a organização tem foco na busca pelo resultado, exigindo maior planejamento, controle e relacionamento interpessoal, com pouco espaço para a criatividade e a análise crítica.

Este resultado pode ser explicado em função do grupo sobre o qual se realizou a pesquisa, voltado para gestores de nível médio, normalmente mais focados nas habilidades técnicas e humanas e nem tanto nas conceituais.

\section{Considerações finais e trabalhos futuros}

Conhecer o modelo mental ou perfil de dominância de aptidões cerebrais é um componente pessoal importante para revelar fraquezas e potencialidades em aspectos motivacionais, de tomada de decisão ou resolução de problemas. Ao conhecer seu perfil, o indivíduo amplia sua autoconsciência e, consequentemente, pode entender melhor porque age de determinada maneira em determinada situação. Para as organizações, conhecer o modelo mental dos empregados é um modo de realizar a adequada gestão do seu capital intelectual, de forma a maximizar suas potencialidades e resultados, alocando-os em funções que podem melhor aproveitar suas características comportamentais.

Neste sentido, este trabalho, realizado com funcionários em nível gerencial tático operacional em uma empresa têxtil de médio porte do Estado de Santa Catarina, não apenas identificou o modelo mental dos funcionários baseado no modelo de Miranda (1997), mas procurou relacioná-lo com as funções ocupadas pelos funcionários e o modelo de competências gerenciais propostos por Quinn et al. (2003). Respondendo à pergunta proposta no início deste artigo, os resultados apresentaram forte aderência entre funções, aptidões cerebrais dominantes e competências gerenciais.

Estes resultados contribuem não apenas para a compreensão sobre o objeto pesquisado, mas também para a própria organização, uma vez que instrumenta a gestão da organização com novos conhecimentos sobre seus colaboradores, relacionando suas capacidades individuais com as competências exigidas para o cargo.

Um exemplo de resultado obtido com este estudo, que pode contribuir significativamente para a gestão do capital intelectual da organização, foi o alcançado na hipótese 5, que revelou setores em que as habilidades humanas estão pouco desenvolvidas. Ao fazer uma análise como a proposta neste estudo, a organização gera um conhecimento que pode auxiliar em decisões de treinamento ou formação de seus funcionários, para desenvolverem este tipo de habilidade requerida na gestão.
No contexto do trabalho, as ferramentas utilizadas baseadas em Miranda (1997) e Quinn et al. (2003) contribuíram de forma positiva neste processo, pois de forma simples e objetiva permitiram identificar e relacionar perfis de aptidões e competências gerenciais.

Alguns cuidados, entretanto, devem ser tomados ao se conduzir e interpretar estudos baseados em modelos mentais. Norman (1990) alerta que modelos mentais são instáveis, incompletos e sem limites rígidos, podendo refletir um momento do indivíduo. Deve-se levar em conta, portanto, a dinamicidade inerente ao contexto das pesquisas realizadas com modelos mentais.

Outro cuidado é quanto à generalização em relação aos resultados alcançados. Nesta organização, especificamente, houve uma convergência em relação às hipóteses de aptidões e competências gerenciais requeridas - com exceção da hipótese 5. Estudos em outras organizações podem conduzir a resultados diferentes, exigindo a ampliação da pesquisa, antes de se estabelecer um modelo genérico que relacionem funções, aptidões e competências.

Por fim, com base nos modelos aqui apresentados, cabem ainda pesquisas mais aprofundadas que relacionem dominância de aptidões cerebrais e competências gerenciais com a performance organizacional. Por se tratar de ativos intangíveis, a gestão do capital intelectual é de difícil mensuração e avaliação. Mas associar o impacto da gestão aqui proposta com o aumento efetivo dos resultados deve ser um objetivo a ser perseguido.

\section{Referências}

ALLINSON, C. W.; ARMSTRONG, S. J.; HAYES, J. The effects of cognitive style on leader-member exchange: a study of manager-subordinate dyads. Journal of Occupational and Organizational Psychology, v. 74, n. 2, p. 201-220, 2001.

ARITZETA, A.; SENIOR, B.; SWAILES, S. Team role preference and cognitive styles: a convergent validity study. Small Group Research, v. 36, n. 4, p. 404-436, 2005.

ARMSTRONG, S. J.; PRIOLA, V. Individual differences in cognitive style and their effects on task and social orientations of self-managed work teams. Small Group Research, v. 32, n. 3, p. 283-312, 2001.

BLASS, E.; HACKSTON, J. Future skills and current realities: how the psychological (Jungian) type of European business leaders relates to the needs of the future. Futures, v. 40, n. 9, p. 822-833, 2008.

CARBONE, P. P.; BRANDÃO, H. P.; LEITE, J. B. D. Gestão por competências e gestão do conhecimento. 2 ed. Rio de Janeiro: Fundação Getúlio Vargas, 2008.

COOLS, E.; BROECK, H. V. D. Cognitive styles and managerial behaviour: a qualitative study. Education and Training, v. 50, n. 2, p. 103-114, 2008. 
CULP, G.; SMITH, A. Understanding psychological type to improve project team performance. Journal of Management in Engineering, v. 17, n. 1, p. 24-33, 2001.

EALES-WHITE, R. M. D. Co-ordination and delegation: the core development competencies to create a competitive edge. Industrial and Commercial Training, v. 37, n. 2, p. 84-90, 2005. (part 1)

FIALHO, F. A. P. Ciências da cognição. Florianópolis: Insular, 2001.

FLEURY, A.; FLEURY, M. T. L. Estratégias empresariais e formação de competências: um quebra cabeça caleidoscópico da indústria brasileira. São Paulo: Atlas, 2000.

FOX, T. L.; SPENCE, J. W. An examination of the decision styles of project managers: evidence of significant diversity. Information \& Management, v. 36, n. 6, p. 313-320, 1999.

GARDNER, H. A nova ciência da mente: uma história da revolução cognitiva. São Paulo: EDUSP, 1996.

GARDNER, W. L.; MARTINKO, M. J. Using the MyersBriggs Type lndicator to study managers: a literature review and research agenda. Journal of Management, v. 22, n. 1, p. 45,83, 1996.

HERRMAN, N. The creative brain. Lake Lure: Brain Books, 1990.

HERRMAN, N. The whole brain business book. New York: McGraw-Hill, 1996.

IRELAND, L. Project manager's competence in emotional intelligence. Colorado: American Society for the Advancement of Project Management, 2006. Disponivel em: <http://www.asapm.org/asapmag/articles/emo_intel. pdf $>$. Acesso em: 22 de agosto de 2009.

JENNINGS, D.; DISNEY, J. J. Designing the strategic planning process: does psychological type matter? Management Decision, v. 44, n. 5, p. 598-614, 2006.
LICHT, R. H. G.; OLIVEIRA, P. S. G.; VENTURA, V. L. S. Avaliação do perfil de empreendedores utilizando a teoria dos tipos psicológicos. Revista Brasileira de Gestão de Negócios, v. 9, n. 24, p. 31-40, 2007.

MATURANA, H.; VARELA, F. J. De máquinas a seres vivos: autopoiese. A organização do vivo. Porto Alegre: Artes Médicas, 1997.

MAXIMIANO, A. C. A. Introdução à administração. 7 ed. São Paulo: Atlas, 2007.

MIRANDA, R. L. Além da inteligência emocional: uso integral das aptidões cerebrais. Rio de Janeiro: Campus, 1997.

MYERS, I. B. et al. MBTI Manual: a guide to the development and use of the Myers-Briggs Type Indicator. Palo Alto: Consulting Psychologists Press, 1998.

NORMAN, D. A. The design of everyday things. New York: Currrency Doubleday, 1990.

PRAHALAD, C. K.; HAMEL, G. The core competences of the corporation. Harvard Business Review, v. 68, n. 3, p. 79-91, 1990.

QUINN, R. E. et al. Competências gerenciais: princípios e aplicações. Rio de Janeiro: Elsevier, 2003.

SABATIER, S.; OPPENHEIM, C. The ILS professional in the City of London: personality and glass ceiling issues. Journal of Librarianship and Information Science, v. 33, n. 3, p. 145-156, 2001.

SENSE, A. J. Learning within project practice: cognitive style exposed. International Journal of Project Management, v. 25, n. 1, p. 33-40, 2007.

STANKOSKY, M. Creating the discipline of knowledge management: the latest in University Research. Burlington: Elsevier, 2005.

THAGARD, P. Mind: introduction to cognitive science. Cambridge: The MIT Press, 1996.

ZARIFIAN, P. Objetivo competência: por uma nova lógica. São Paulo: Atlas, 2001. 


\section{Anexo 1}

Exemplos das questões 3 e 5 do questionário de Aptidões Cerebrais proposto por Miranda (1997, p. 105-106):

Atividades de minha preferência no TRABALHO (assinale quatro):

\begin{tabular}{|l|l|}
\hline 01. ( ) Administração de Processos & 09. ( ) Ensinar/Treinar \\
\hline 02. ( ) Análise de Problemas & 10. ( ) Orçamentos \\
\hline 03. ( ) Assuntos Administrativos & 11. ( ) Planejamento de Atividades \\
\hline 04. ( ) Assuntos Técnicos & 12. ( ) Planejamento estratégico \\
\hline 05. ( ) Estruturas/Organização & 13. ( ) Propaganda \\
\hline 06. ( ) Assuntos Humanos/Sociais & 14. ( ) Relações Públicas \\
\hline 07. ( ) Assuntos Financeiros & 15. ( ) Testes de Mercado \\
\hline 08. ( ) Criação/Desenvolvimento de Ideias & 16. ( ) Trabalhos em Equipe \\
\hline
\end{tabular}

05. Meus DESCRITIVOS (assinale quatro):

\begin{tabular}{|l|l|l|l|}
\hline 01. ( ) Afetuoso & 05. ( ) Detalhista & 09. ( ) Falante & 13. ( ) Organizado \\
\hline 02. ( ) Analítico & 06. ( ) Emotivo & 10. ( ) Fantasioso & 14. ( ) Racional \\
\hline 03. ( ) Brincalhão & 07. ( ) Esmerado & 11. ( ) Introvertido & 15. ( ) Subjetivo \\
\hline 04. ( ) Cauteloso & 08. ( ) Extrovertido & 12. ( ) Intuitivo & 16. ( ) Técnico \\
\hline
\end{tabular}

